\title{
Impact of oral anticoagulation on clinical outcomes of COVID-19: a nationwide cohort study of hospitalized patients in Germany
}

\author{
Georg M. Fröhlich ${ }^{1}$ D · Elke Jeschke ${ }^{2}$. Uwe Eichler ${ }^{2} \cdot$ Holger Thiele $^{3} \cdot$ Laila Alhariri $^{4} \cdot$ Markus Reinthaler $^{1}$. \\ Adnan Kastrati ${ }^{5}$. David Manuel Leistner ${ }^{1,6}$. Carsten Skurk ${ }^{1,6}$. Ulf Landmesser ${ }^{1,6,7}$. Christian Günster ${ }^{2}$
}

Received: 15 September 2020 / Accepted: 18 November 2020 / Published online: 8 January 2021

○) Springer-Verlag GmbH Germany, part of Springer Nature 2021

\begin{abstract}
Objectives The aim of this study was to investigate the impact of concomitant long-term medication-with a focus on ACE inhibitors and oral anticoagulation—on clinical outcomes in patients hospitalized with coronavirus disease 2019.

Methods This is a retrospective cohort study using claims data of the biggest German health insurance company AOK, covering 26.9 million people all over Germany. In particular, patient-related characteristics and co-medication were evaluated. A multivariable logistic regression model was adopted to identify independent predictors for the primary outcome measure of all-cause mortality or need for invasive or non-invasive ventilation or extracorporeal membrane oxygenation.

Results 6637 patients in 853 German hospitals were included. The primary outcome occurred in 1826 patients $(27.5 \%)$. 1372 patients $(20.7 \%)$ died, 886 patients (13.3\%) needed respiratory support, and 53 patients $(0.8 \%)$ received extracorporeal membrane oxygenation. 34 of these patients survived (64.2\%). The multivariable model demonstrated that pre-existing oral anticoagulation therapy with either vitamin-K antagonists OR 0.57 (95\% CI $0.40-0.83, p=0.003$ ) or direct oral anticoagulants OR 0.71 (95\% CI 0.56-0.91, $p=0.007$ )—but not with antiplatelet therapy alone OR 1.10 (95\% CI 0.88-1.23, $p=0.66$ )—was associated with a lower event rate. This finding was confirmed in a propensity match analysis.

Conclusions In a multivariable analysis, a therapy with both direct oral anticoagulants or vitamin-K antagonists-but not with antiplatelet therapy—was associated with improved clinical outcomes. ACE inhibitors did not impact outcomes. Prospective randomized trials are needed to verify this hypothesis.
\end{abstract}

Supplementary Information The online version contains supplementary material available at https://doi.org/10.1007/s0039 2-020-01783-x.

Georg M. Fröhlich

georg.froehlich@charite.de

1 Department of Cardiology, Charité-Universitätsmedizin Berlin, Campus Benjamin Franklin, Hindenburgdamm 30, 12203 Berlin, Germany

2 AOK Research Institute (WIdO), Berlin, Germany

3 Heart Center Leipzig at University of Leipzig and Leipzig Heart Institute, Leipzig, Germany

4 School of Medicine, University Hospital Dresden, Dresden, Germany

5 Deutsches Herzzentrum München, Munich, Germany

6 DZHK Partner Site Berlin, Berlin, Germany

7 Berlin Institute of Health (BIH), Anna-Louisa-Karsch-Straße 2, 10178 Berlin, Germany 


\section{Graphic abstract}

Impact of long-term oral anticoagulation on clinical outcomes in COVID-19

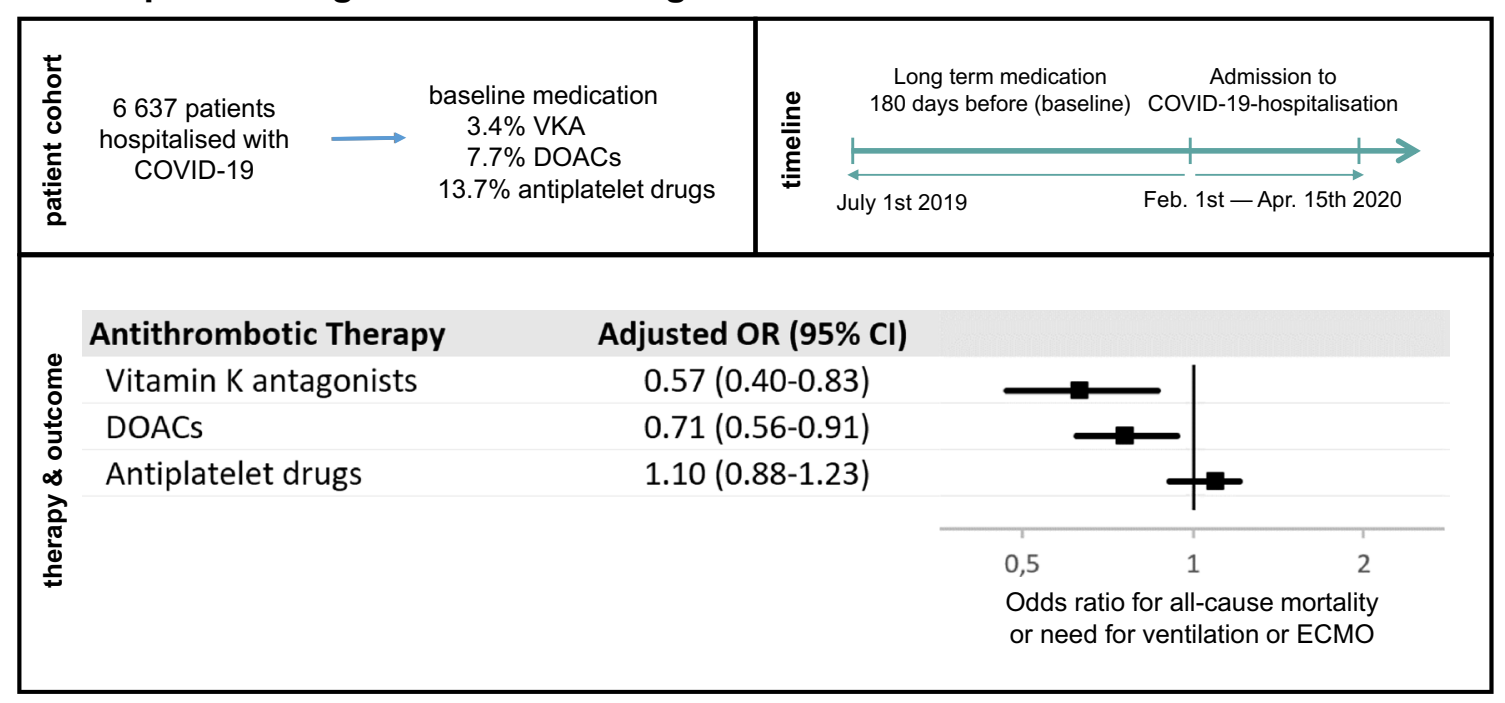

Keywords COVID-19 $\cdot$ DOACs · Vitamin-K-antagonist · Antiplatelet therapy $\cdot$ ACE inhibitors · ECMO

\section{Introduction}

The coronavirus disease 2019 (COVID-19) pandemic is affecting people in 188 countries worldwide [1]. Globally, more than 27 million patients were tested positive for the new severe acute respiratory syndrome coronavirus 2 (SARS-CoV-2), and more than 900,000 people deceased from COVID-19 [1]. The first case series were reported from the metropolitan area of Wuhan (China) [2]. Older age, hypertension, diabetes, and cardiovascular comorbidities were found-amongst others-to be risk factors for an unfavorable course of COVID-19 [2]. But also several widely used drugs, such as different antithrombotic therapies, may be associated with outcomes [3], as data from autopsy studies demonstrated an excess rate of thromboembolic events in COVID-19 patients [4-6].

While patient characteristics were reported from different countries during the SARS-CoV-2 pandemic, these data are still sparse for Germany. In this first large-scale German analysis, patient-related parameters and the concomitant medication were of interest.

\section{Methods}

\section{AOK database characteristics}

All data are derived from the database of the Allgemeine Ortskrankenkasse (AOK) health insurance company. The AOK is the main German provider of statutory health insurance for about 26.9 million people, which represents about one-third of the whole German population. In the present analysis, nationwide claim data for in-patient treatment and out-patient prescriptions were used. Hospital data included patient characteristics, main diagnoses, procedures (non-invasive and invasive ventilation, and extracorporeal membrane oxygenation [ECMO]), complications, admission date and length of hospital stay, as well as comorbidities or death. Diagnoses were encoded according to the International Classification of Diseases (ICD-10) [7]. Procedures were documented using the German version of the International Classification of Procedures in Medicine (ICPM), the OPS code [8]. Healthcare and health insurance providers follow guidelines for coding of diagnoses and procedures in German hospitals. Hospital data in Germany are thoroughly checked against these guidelines and for plausibility by hospitals and sickness funds and returned to hospitals for correction if necessary. 


\section{Study population}

All patients registered in the AOK database who were $>18$ years of age and who were admitted to an acute care hospital between February 1st, 2020 and April 15th, 2020 with a confirmed diagnosis of COVID-19 were eligible for study inclusion (ICD-10 U07.1). A test result was usually considered "positive" if SARS-CoV-2 RNA was detectable in a nasal and/or pharyngeal swab by polymerase chain reaction (PCR). Only completed hospitalizations (either "discharged", "alive" or "deceased") until April 28th, 2020 were analyzed.

\section{Drug exposure}

The long-term medication was assessed by claim data. Drugs are routinely encoded according to the WHO ATC/ DDD Index 2020 (German modification) [9]. Drug exposure at baseline was defined as prescription of $\geq 90$ defined daily doses (DDDs) within 180 days prior to the index hospitalization for COVID-19. This reflects the fact that long-term medication is often prescribed and dispensed in 3 -month supplies (90 DDDs). Consequently, a minimum of one such prescription is to be expected during a 180-day interval, but two may not be documented during the exact interval, since prescriptions may be issued days or weeks prior to being filled.

As a sensitivity analysis, drug exposure windows of 180 and 365 days were compared.

The following drug classes were monitored: antihypertensive medication (angiotensin-converting enzyme inhibitors [ACEI], angiotensin-receptor blocker [ARB], mineralocorticoid receptor antagonists [MRA], calcium channel blockers [CCB], $\beta$-blockers [BB], renin inhibitors [RI], statins, and diuretics other than MRA), antithrombotic medication (Vitamin K antagonists [VKA], direct oral anticoagulants [DOACs], antiplatelet drugs), insulin and non-insulin anti-diabetics, and immunosuppressants. ATC-Codes that were used for the current study are shown in online resource 1 in the online-only appendix.

\section{Outcome measures}

The primary outcome measure was defined as all-cause mortality or need for non-invasive or invasive ventilation (OPS codes 8-701, 8-704, and 8-706) or ECMO (OPS code 8-852).

Secondary outcome measures were all-cause mortality, invasive (OPS 8-701, 8-704), or non-invasive ventilation (OPS code 8-706), need for ECMO, acute respiratory distress syndrome (ARDS, ICD-10: J80.X), and septic shock (ICD-10: R65.0, R65.1, R65.9, R57.2).

Potential complications during the hospitalization including acute myocardial infarction (ICD-10: I21.X), myocarditis (ICD-10: I40.X, I41.1), pulmonary edema (ICD-10: J81.X), pulmonary embolism (ICD-10 I26.X), deep vein thrombosis (ICD-10: I80.1, I80.2, I80.3, I82.2), stroke (ICD10: I63.X), or need for hemofiltration (OPS code 5-553) were identified. The data did not allow to determine if these complications were directly related to the COVID-19 or if they occurred independently.

\section{Statistical analysis}

Descriptive statistics including medians, interquartile ranges (IQRs), and proportions were used to describe the study sample. Subgroup analyses were performed for patient age ( $<60$ years, $60-79$ years, and $\geq 80$ years), as well as for medication groups (ACEIs/ACBs, VKA, DOACs, and antiplatelet drugs).

Multivariable logistic regression was used to model the odds of outcomes as a function of drug exposure. Adjusted odds ratios (OR) and $95 \%$ confidence intervals $(\mathrm{CI})$ were calculated. Patient age, gender, body mass index (BMI), comorbidities, and immunosuppressive agents prior to the hospital stay were included as independent variables. The Elixhauser conditions to predict mortality from administrative data were adopted for the definition of comorbidities [10]. The definition includes 31 acute and chronic diseases which were implemented using the coding algorithm by Quan et al. based on ICD-10 coding [11]. Some minor deviations from the Elixhauser conditions included separated BMI categories $\left(<30,30-34,35-39, \geq 40 \mathrm{~kg} / \mathrm{m}^{2}\right)$ rather than a variable obesity. Similarly, cardiac arrhythmia was split into atrial fibrillation and other cardiac arrhythmias. Myocardial infarction and stroke were included as independent variables. Elixhauser conditions were defined on in-patient diagnoses. Patients with hypertension were identified by outpatient diagnoses in at least two quarters between July 1st, 2018 and January 31st, 2020, and documented antihypertensive medication prior to COVID-19 hospitalization. All comorbidities were entered as separate dichotomous variables. A $p$ value $<0.05$ was considered significant.

To further address confounding in the observational data, a sensitivity analysis was conducted by comparing patients with antithrombotic treatment with DOACs or VKA to a propensity score-matched control group. A propensity score was calculated to estimate the likelihood of antithrombotic treatment with models that adjusted for patient characteristics, comorbidities, and medication, as in the multivariable logistic regression model. According to the estimated propensity scores, patients on oral anticoagulation were matched to those without any antithrombotic therapy using 
a 1:1 ratio with replacement. The nearest-neighbor strategy without caliper was used for matching. Balance of covariates for patients before and after matching on propensity scores was checked. The treatment effect was computed by taking the average of the difference between the observed and potential primary outcomes for each subject. All analyses were performed using STATA 16.0 (StataCorp LP, College Station, Texas).

\section{Results}

In total, 6637 patients $>18$ years of age were admitted to 853 acute care hospitals all over Germany between February 1st, 2020 and April 15th, 2020 with a confirmed diagnosis of COVID-19.

\section{Baseline characteristics}

Altogether, 2108 patients (31.8\%) were younger than 60 years; 1,124 patients $(16.9 \%)$ were $60-69$ years old; 1 384 patients (20.9\%) were in the age group of 70-79 years; 1,670 patients $(25.2 \%)$ were $80-89$ years old; and 351 patients $(5.3 \%) \geq 90$ years. Overall, 508 patients $(7.7 \%$ of the study population) received a DOAC and 223 patients received a VKA (3.4\%). The main reason for anticoagulation was the presence of atrial fibrillation in 501 patients $(68.5 \%$ of patients with anticoagulation). Table 1 gives an overview of the most important baseline characteristics according to antithrombotic medication. Online resource 2 shows detailed patient characteristics.

\section{Outcome measures}

The primary outcome measure was met in 1826 patients (27.5\%). The secondary outcome measure of all-cause mortality occurred in 1372 patients (20.7\%); 839 patients (12.6\%) needed ventilatory support and non-invasive ventilation was used in 119 patients (1.8\%), while invasive ventilation was applied in 720 patients (10.8\%). ECMO therapy was used in 53 patients $(0.8 \%)$. An ARDS was documented in 667 patients (10.0\%), and 693 patients (10.4\%) were treated for septic shock. Table 2 summarizes the most important outcomes.

In patients with DOAC or VKA, the primary outcome measure was met in 182 patients (35.8\%) and 64 patients (34.6\%), respectively. 161 patients (31.7\%) with DOAC and 56 patients (30.3\%) with VKA died in hospital (Table 3).

\section{Complications}

Cardiovascular complications comprised acute myocardial infarction in 99 patients (1.5\%); 47 of them died (47.5\%).
Myocarditis was diagnosed in 13 patients $(0.2 \%) ; 7$ of them died (53.8\%). Pulmonary embolism was clinically detected in 83 patients (1.3\%) and deep vein thrombosis occurred in 44 patients $(0.7 \%)$. Of the patients with thromboembolic events, 32 patients died (28.1\%). Pulmonary edema was present in 6 patients $(0.1 \%)$ and stroke in 72 patients $(1.1 \%)$. Hemofiltration was uncommon and became necessary in 13 patients $(0.2 \%)$.

\section{Multivariable logistic regression model to assess for independent risk factors for the occurrence of the primary outcome measure}

The results of the logistic regression model are presented in Fig. 1. Adjusted for age, gender, and comorbidities, patients with DOACs (OR 0.71; 0.56-0.91) and VKA (OR 0.57; $0.40-0.83$ ) had a lower risk for the primary endpoint, while antiplatelet drugs showed no significant effect.

The propensity-matched sensitivity analysis for the effect of oral anticoagulation on the occurrence of the primary endpoint showed a median risk difference of -0.0972 $(-0.1613$ to -0.0330$)$ between 666 matched patients with antithrombotic treatment with DOACs or VKA in comparison to the propensity score-matched control group. The balance of covariates for patients before and after propensity-score matching is shown in the online resource 2 . The standardized mean differences for each class of medication were greatly reduced after matching.

\section{Subsets of patients that need special consideration}

\section{Deceased patients (online resource 3)}

Altogether, 1372 patients died (20.7\%). The main causes for death were ARDS $(n=316,23.0 \%)$, septic shock $(n=349$, $25.4 \%)$, and myocardial infarction $(n=47,3.4 \%)$. Some of the patients had more than one condition that was considered as a cause of death. The median age was 81 years (IQR 76-86 years); 566 patients were female (41.3\%). The most common comorbidities were hypertension in 1136 patients (82.8\%), kidney failure in 507 patients (37.0\%), diabetes in 496 patients (36.2\%), atrial fibrillation in 457 patients (33.3\%), heart failure in 431 patients $(31.4 \%)$, and pulmonary circulatory disorders were present in 196 patients (14.3\%). Out of the deceased patients, $436(31.8 \%)$ had non-invasive or invasive ventilation. On the contrary, 936 patients (68.2\%) who died were not ventilated.

\section{Patients $<60$ years of age who died or who needed respiratory support}

In total, 241 patients (3.6\%) were younger than 60 years of age. Their median age was 53 years (IQR 47-56). Their 
Table 1 Characteristics of the study population of hospitalized patients with COVID-19* according to antithrombotic therapy

\begin{tabular}{|c|c|c|c|c|c|c|}
\hline \multirow[t]{2}{*}{ Characteristic } & \multirow[t]{2}{*}{ All patients $(N=6637)$} & \multirow[t]{2}{*}{ Without AT $(N=5059)$} & \multicolumn{4}{|l|}{ With AT } \\
\hline & & & Total $(N=1.578)$ & $\begin{array}{l}\text { Vitamin K } \\
\text { antagonists } \\
(N=223)\end{array}$ & DOACs $(N=508)$ & $\begin{array}{l}\text { Antiplate- } \\
\text { let drugs } \\
(N=912)\end{array}$ \\
\hline Age (y), median (IQR) & $70(55-81)$ & $65(52-79)$ & $79(71-85)$ & $80(75-85)$ & $80(75-85)$ & $79(69-84)$ \\
\hline Female sex, $n(\%)$ & $3132(47.2)$ & $2475(48.9)$ & $657(41.6)$ & $95(42.6)$ & $256(50.4)$ & $330(36.2)$ \\
\hline \multicolumn{7}{|l|}{ BMI $\left(\mathrm{kg} / \mathrm{m}^{2}\right), n(\%)$} \\
\hline$<30$ & $6305(95.0)$ & $4817(95.2)$ & $1486(94.2)$ & $206(92.4)$ & $478(93.3)$ & $867(95.1)$ \\
\hline $30-34$ & $169(2.5)$ & $116(2.3)$ & $53(3.4)$ & $9(4.0)$ & $22(4.3)$ & $23(2.5)$ \\
\hline $35-39$ & $83(1.3)$ & $64(1.3)$ & $19(1.2)$ & $1(0.4)$ & $7(1.4)$ & $11(1.2)$ \\
\hline$\geq 40$ & $82(1.2)$ & $62(1.2)$ & $20(1.3)$ & $7(3.1)$ & $5(1.0)$ & $10(1.1)$ \\
\hline \multicolumn{7}{|l|}{$\begin{array}{l}\text { Comorbidities } * *, n \\
\quad(\%)\end{array}$} \\
\hline Hypertension & $4259(64.2)$ & $2802(55.4)$ & $1457(92.3)$ & $211(94.6)$ & $468(92.1)$ & 838 (91.9) \\
\hline $\begin{array}{l}\text { Fluid and electrolyte } \\
\text { disorders }\end{array}$ & 2977 (44.9) & $2143(42.4)$ & $834(52.9)$ & $116(52.0)$ & $259(51.0)$ & $488(53.5)$ \\
\hline Diabetes mellitus & $1716(25.9)$ & $1,065(21.1)$ & $651(41.3)$ & $91(40.8)$ & $184(36.2)$ & $405(44.4)$ \\
\hline Uncomplicated & $1263(19.0)$ & $838(16.6)$ & 425 (26.9) & $61(27.4)$ & $132(26.0)$ & $247(27.1)$ \\
\hline Complicated $* * *$ & $453(6.8)$ & $227(4.5)$ & $226(14.3)$ & $30(13.5)$ & $52(10.2)$ & $158(17.3)$ \\
\hline Cardiac arrhythmia & $1484(22.4)$ & 741 (14.6) & $743(47.1)$ & $174(78.0)$ & $372(73.2)$ & $239(26.2)$ \\
\hline Atrial fibrillation & $1189(17.9)$ & $548(10.8)$ & $641(40.6)$ & $165(74.0)$ & $348(68.5)$ & $169(18.5)$ \\
\hline $\begin{array}{l}\text { Other cardiac } \\
\text { arrhythmia }\end{array}$ & $295(4.4)$ & $193(3.8)$ & $102(6.5)$ & $9(4.0)$ & $24(4.7)$ & $70(7.7)$ \\
\hline Renal failure & $1300(19.6)$ & 754 (14.9) & $546(34.6)$ & $98(43.9)$ & $150(29.5)$ & $321(35.2)$ \\
\hline $\begin{array}{l}\text { Congestive heart } \\
\text { failure }\end{array}$ & $1017(15.3)$ & $546(10.8)$ & $471(29.8)$ & $82(36.8)$ & 167 (32.9) & $245(26.9)$ \\
\hline Hypothyroidism & 901 (13.6) & $669(13.2)$ & $232(14.7)$ & $35(15.7)$ & $78(15.4)$ & $129(14.1)$ \\
\hline $\begin{array}{l}\text { Chronic pulmonary } \\
\text { disease }\end{array}$ & $815(12.3)$ & $542(10.7)$ & $273(17.3)$ & 37 (16.6) & $95(18.7)$ & $153(16.8)$ \\
\hline $\begin{array}{l}\text { Neurological disor- } \\
\text { ders }\end{array}$ & $438(6.6)$ & $285(5.6)$ & $153(9.7)$ & $17(7.6)$ & $46(9.1)$ & $94(10.3)$ \\
\hline $\begin{array}{l}\text { Peripheral vascular } \\
\text { disorders }\end{array}$ & $374(5.6)$ & $166(3.3)$ & $208(13.2)$ & $28(12.6)$ & $56(11.0)$ & $147(15.6)$ \\
\hline Depression & $345(5.2)$ & $255(5.0)$ & $90(5.7)$ & $11(4.9)$ & $25(4.9)$ & $57(6.3)$ \\
\hline Valvular disease & $280(4.2)$ & $146(2.9)$ & $134(8.5)$ & $47(21.1)$ & $36(7.1)$ & $58(6.4)$ \\
\hline Coagulopathy & $263(4.0)$ & $172(3.4)$ & $91(5.8)$ & 37 (16.6) & $26(5.1)$ & $32(3.5)$ \\
\hline Paralysis & $224(3.4)$ & $127(2.5)$ & $97(6.1)$ & $5(2.2)$ & $32(6.3)$ & $63(6.9)$ \\
\hline Liver disease & $205(3.1)$ & $156(3.1)$ & $49(3.1)$ & $6(2.7)$ & $12(2.4)$ & $34(3.7)$ \\
\hline $\begin{array}{l}\text { Pulmonary circula- } \\
\text { tion disorders }\end{array}$ & $187(2.8)$ & $127(2.5)$ & $60(3.8)$ & $11(4.9)$ & $24(4.7)$ & $27(3.0)$ \\
\hline $\begin{array}{l}\text { Solid tumor without } \\
\text { metastasis }\end{array}$ & $186(2.8)$ & $129(2.5)$ & $57(3.6)$ & $11(4.9)$ & $21(4.1)$ & $28(3.1)$ \\
\hline $\begin{array}{l}\text { Iron deficiency } \\
\text { anemia }\end{array}$ & $186(2.8)$ & $116(2.3)$ & $70(4.4)$ & $5(2.2)$ & $29(5.7)$ & $42(4.6)$ \\
\hline Weight loss & $173(2.6)$ & $117(2.3)$ & $56(3.5)$ & $8(3.6)$ & $14(2.8)$ & $37(4.1)$ \\
\hline \multicolumn{7}{|l|}{ History of } \\
\hline $\begin{array}{l}\text { Myocardial infarc- } \\
\text { tion }\end{array}$ & $205(3.1)$ & $80(1.6)$ & $125(7.9)$ & $13(5.8)$ & $16(3.1)$ & $102(11.2)$ \\
\hline Stroke & $177(2.7)$ & $82(1.6)$ & $95(6.0)$ & $6(2.7)$ & $31(6.1)$ & $61(6.7)$ \\
\hline \multicolumn{7}{|l|}{ Medications, $n(\%)$} \\
\hline $\begin{array}{l}\text { Antihypertensive } \\
\text { drugs }\end{array}$ & 3977 (59.9) & $2529(50.0)$ & $1448(91.8)$ & 205 (91.9) & $457(90.0)$ & $848(93.0)$ \\
\hline ACEIs/ARBs & 2935 (44.2) & $1896(37.5)$ & $1.039(65.8)$ & $148(66.4)$ & $325(64.0)$ & $619(67.9)$ \\
\hline
\end{tabular}


Table 1 (continued)

\begin{tabular}{|c|c|c|c|c|c|c|}
\hline \multirow[t]{2}{*}{ Characteristic } & \multirow[t]{2}{*}{ All patients $(N=6637)$} & \multirow[t]{2}{*}{ Without AT $(N=5059)$} & \multicolumn{4}{|l|}{ With AT } \\
\hline & & & Total $(N=1.578)$ & $\begin{array}{l}\text { Vitamin K } \\
\text { antagonists } \\
(N=223)\end{array}$ & DOACs $(N=508)$ & $\begin{array}{l}\text { Antiplate- } \\
\text { let drugs } \\
(N=912)\end{array}$ \\
\hline $\begin{array}{l}\text { Other antihyperten- } \\
\text { sive drugs }\end{array}$ & $1042(15.7)$ & $633(12.5)$ & 409 (25.9) & $57(25.6)$ & $132(26.0)$ & $229(25.1)$ \\
\hline $\begin{array}{l}\text { Immunosuppressive } \\
\text { agents }\end{array}$ & $311(4.7)$ & $200(4.0)$ & $111(7.0)$ & $15(6.7)$ & $37(7.3)$ & $66(7.2)$ \\
\hline Antidiabetic agents & $1145(17.3)$ & $689(13.6)$ & $456(28.9)$ & $68(30.5)$ & $128(25.2)$ & $286(31.4)$ \\
\hline Insulin & $460(6.9)$ & $241(4.8)$ & $219(13.9)$ & $30(13.5)$ & $54(10.6)$ & $146(16.0)$ \\
\hline $\begin{array}{l}\text { Other hypoglycemic } \\
\text { agents }\end{array}$ & 839 (12.6) & $531(10.5)$ & $308(19.5)$ & $50(22.4)$ & $92(18.1)$ & $187(20.5)$ \\
\hline
\end{tabular}

$B M I$ body mass index, $A C E I$ angiotensin-converting enzyme inhibitor, $A R B$ angiotensin-receptor blocker, $D O A C$ directly acting oral anticoagulants

*Positive test for COVID-19

**Double entries are possible; sorted by descending frequency; other comorbidities with a frequency $<2.0 \%$ in the whole cohort are not shown (blood loss anemia, peptic ulcer disease excluding bleeding, lymphoma, metastatic cancer, rheumatoid arthritis, alcohol abuse, drug abuse, psychoses, and AIDS/HIV)

*** i.e., coma, ketoacidosis, and vascular disease

Table 2 Primary and secondary outcomes of hospitalized patients with COVID-19 stratified for age group

\begin{tabular}{|c|c|c|c|c|}
\hline \multirow[t]{2}{*}{ Endpoint } & \multirow[t]{2}{*}{ All patients $(N=6.637)$} & \multicolumn{3}{|l|}{ Age (y) } \\
\hline & & $<60(N=2.108)$ & $60-79(N=2.508)$ & $\geq 80(N=2.021)$ \\
\hline Primary outcome*, $n(\%)$ & $1.826(27.5)$ & $241(11.4)$ & $698(27.8)$ & $887(43.9)$ \\
\hline \multicolumn{5}{|l|}{ Secondary outcomes, $n(\%)$} \\
\hline In-hospital all-cause mortality & $1.372(20.7)$ & $59(2.8)$ & $484(19.3)$ & $829(41.0)$ \\
\hline Need for non-invasive ventilation & $119(1.8)$ & $23(1.1)$ & $51(2.0)$ & $45(2.2)$ \\
\hline Need for invasive ventilation & $720(10.8)$ & $165(7.8)$ & $389(15.5)$ & $166(8.2)$ \\
\hline ECMO & $53(0.8)$ & $31(1.5)$ & $19(0.8)$ & $3(0.1)$ \\
\hline ARDS & $667(10.1)$ & $175(8.3)$ & $325(13.0)$ & $167(8.3)$ \\
\hline Septic shock & $693(10.4)$ & $150(7.1)$ & $333(13.3)$ & $210(10.4)$ \\
\hline
\end{tabular}

$E C M O$ extracorporeal membrane oxygenation, $A R D S$ acute respiratory distress syndrome

*In-hospital all-cause mortality or need for invasive or non-invasive ventilation or ECMO implant

main comorbidities were hypertension in 112 patients (46.5\%), diabetes in 60 patients $(24.9 \%)$, obesity in 32 patients (13.3\%), cardiac arrhythmia in 30 patients (12.4\%), and congestive heart failure in 29 patients (12.0\%).

\section{Patients on ECMO therapy}

Of the 53 patients $(0.8 \%)$ receiving ECMO therapy, the median age was 57 years (IQR 50-67); 36 patients were male $(67.9 \%)$. Overall, 19 patients died $(35.8 \%)$. Time on ECMO was $<48 h$ in 15 patients (28.3\%), 2-12 days in 25 patients (47.2\%), and $12-32$ days in 8 patients (15.1\%). In the age group $<60$ years, 31 patients received ECMO therapy (58.5\% of ECMO patients) and 23 patients $(74.2 \%)$ of them survived. In the age group $\geq 60$ years of age, 22 patients
(41.5\% of ECMO patients) were treated with ECMO. Their median age was 68.5 years (IQR 64-74 years). In this age group, 11 patients survived $(50.0 \%)$.

\section{Discussion}

This is a large nationwide observational study including more than 6500 patients hospitalized for COVID-19 in Germany. The all-cause mortality rate equaled $20.7 \%$. In patients who needed respiratory support, the mortality rate reached $49.1 \%$. Notably, an antithrombotic treatment with both DOACs or VKA - but not with antiplatelet therapywas associated with improved clinical outcomes. The use of 
Table 3 Outcome of hospitalized patients with COVID-19 according to antihypertensive and antithrombotic medication

\begin{tabular}{|c|c|c|c|c|c|c|c|}
\hline \multirow[t]{2}{*}{ Endpoint } & \multicolumn{3}{|c|}{ Antihypertensive drugs } & \multicolumn{4}{|l|}{ Anti-thrombotics } \\
\hline & All $(N=3.977)$ & $\begin{array}{l}\text { ACEIs/ARBs } \\
(N=2.935)\end{array}$ & $\begin{array}{l}\text { Other hyperten- } \\
\text { sive drugs (only) } \\
(N=1.042)\end{array}$ & All $(N=1.578)$ & $\begin{array}{l}\text { Vitamin K } \\
\text { antagonists } \\
(N=223)\end{array}$ & DOACs $(N=508)$ & $\begin{array}{l}\text { Antiplate- } \\
\text { let drugs } \\
(N=912)\end{array}$ \\
\hline $\begin{array}{l}\text { Primary outcome*, } \\
n(\%)\end{array}$ & $1384(34.8)$ & $990(33.7)$ & $394(37.8)$ & 601(38.1) & $82(36.8)$ & $182(35.8)$ & $366(40.1)$ \\
\hline \multicolumn{8}{|l|}{$\begin{array}{l}\text { Secondary out- } \\
\text { comes, } n(\%)\end{array}$} \\
\hline $\begin{array}{l}\text { All-cause mortal- } \\
\text { ity }\end{array}$ & $1.113(28.8)$ & 781 (26.6) & 332 (31.9) & $520(33.0)$ & $72(32.3)$ & 161(31.7) & $314(34.4)$ \\
\hline $\begin{array}{l}\text { Need for non-inva- } \\
\text { sive ventilation }\end{array}$ & $82(2.1)$ & $56(1.9)$ & $26(2.5)$ & $39(2.5)$ & $4(1.8)$ & $11(2.2)$ & $25(2.7)$ \\
\hline $\begin{array}{l}\text { Need for invasive } \\
\text { ventilation }\end{array}$ & 507 (12.7) & 399 (13.6) & $108(10.4)$ & 169 (10.7) & $27(12.1)$ & $50(9.8)$ & 99 (10.9) \\
\hline ECMO & $31(0.8)$ & $20(0.7)$ & $11(1.1)$ & $10(0.6)$ & $0(0.0)$ & $1(0.2)$ & $9(1.0)$ \\
\hline ARDS & 452 (11.4) & $352(12.0)$ & $100(9.6)$ & $155(9.8)$ & $23(10.3)$ & $41(8.1)$ & 97 (10.6) \\
\hline Septic shock & $477(12.0)$ & 343 (11.7) & $134(12.9)$ & $201(12.7)$ & $29(13.0)$ & $52(10.2)$ & $127(13.9)$ \\
\hline
\end{tabular}

$A C E I$ angiotensin-converting enzyme inhibitor, $A R B$ angiotensin-receptor blocker, DOAC directly acting oral anticoagulants, ECMO extracorporeal membrane oxygenation, $A R D S$ acute respiratory distress syndrome

*In-hospital all-cause mortality or need for invasive or non-invasive ventilation or ECMO implant

antihypertensive drugs, like ACE inhibitors or angiotensinreceptor antagonists, did not impact outcomes.

The median age of patients hospitalized for COVID-19 was 70 years and $12.6 \%$ of patients needed non-invasive $(0.8 \%)$ or invasive ventilation $(10.8 \%)$ in an intensive-care unit. ARDS and septic shock were frequent in this patient group, while the occurrence of acute myocardial infarction was uncommon.

The first German patient with PCR-confirmed SARSCoV-2 infection was reported on 27th January 2020 [12]. As of the 18th October 2020, more than 360000 patients were tested positive and over 9700 patients deceased with COVID-19 in Germany [1]. German health care authority data suggested that only $8-10 \%$ of the patients with SARS$\mathrm{CoV}-2$ infection needed hospitalization, while the majority of patients experienced mild symptoms or remained asymptomatic [13]. This finding highlights the sickest group of patients who need hospitalization.

The in-hospital mortality rate is in line with the previous reports from Germany (22\%) and a comparable patient cohort from New York, where $21 \%$ of in-patients with COVID-19 died [14, 15]. Interestingly, the majority of deceased German patients did not receive ventilation, which may be explained by a palliative treatment approach. This finding is remarkable and may impact on the future development of ICU resources. It is indeed common in Germany that even old and frail patients from nursery homes are admitted to hospital rather, than to receive pure palliation at home as end-of-life care [16]. Older age crystallized as the most important prognostic factor in COVID-19 patients. In line with recent previous studies, the present analysis confirmed that patients with pre-existing heart failure or cardiac arrhythmia, diabetes, obesity, organ failure, malignancies, or neurological disorders were at a pronounced risk for adverse outcome [17, 18]. While arterial hypertension was present in a majority of patients, it appeared as an indicator for older age and more frequent comorbidities rather than representing an independent risk factor.

Surprisingly, depression appeared to reduce the risk to meet the primary outcome in the present study. Interestingly, several antidepressants like clomipramin or fluoxetin were suggested as a potential therapy in patients with COVID-19 to prevent neurologic complications due to their anti-inflammatory properties $[19,20]$. Currently, a randomized trial is aiming to recruit 2000 patients with COVID-19 to investigate the SSRI fluoxetin in this setting (NCT04377308). However, it was beyond the aim of this study to examine the impact of antidepressant and neuroleptic drugs on the course of disease in COVID-19.

ACEI and ARB therapy were suspected of deteriorating the course of COVID-19, until several large observational studies disproved this hypothesis recently [21,22]. Similarly, in the German COVID-19 patient cohort, therapy with antihypertensive drugs did not impact the course of the disease.

In contrast, long-term oral anticoagulation either with DOACs or with VKA was independently associated with improved outcomes. COVID-19 triggers a pro-coagulatory state that increases the risk for thromboembolic events, and might be highly relevant for the clinical course of disease [3, 23]. The main indication for a long-term oral anticoagulation 


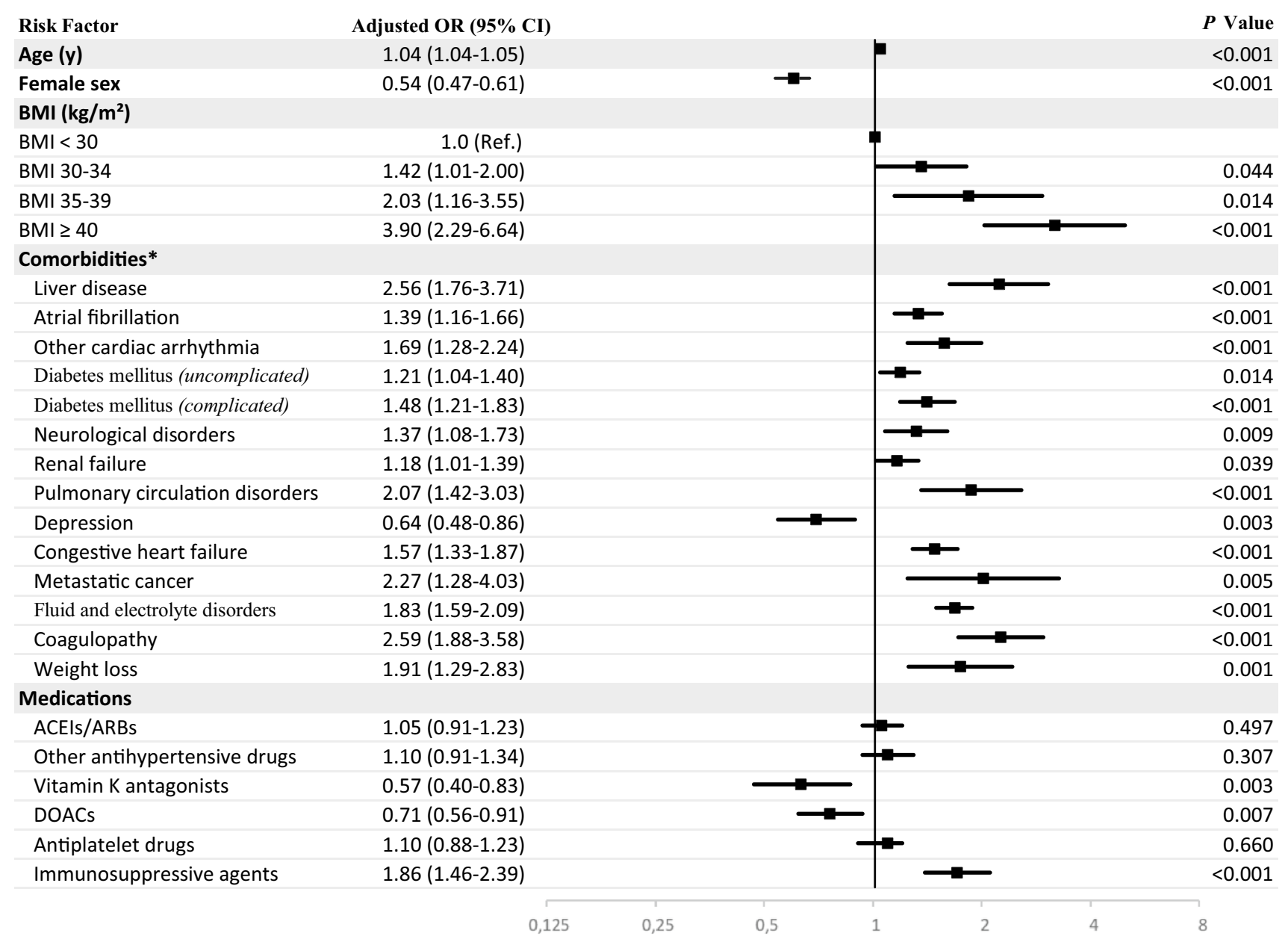

Fig. 1 Multivariable logistic regression analysis for the primary outcome measure. $C I$ confidence interval, $O R$ odds ratio, $B M I$ body mass index, $A C E I$ angiotensin-converting enzyme inhibitor, $A R B$ angioten-

in the German dataset was atrial fibrillation. The risk of adverse outcome for patients with atrial fibrillation is enhanced independently of a therapy with VKA or DOACs. Indeed, atrial fibrillation is a marker of more severe cardiac disease, and frequently, atrial fibrillation is associated with significant non-cardiac comorbidities [24]. We hypothesize that the reduction of thromboembolic complications, in particular pulmonary embolism, might be the main driver for the favorable outcome associated with VKA and DOACs. However, due to the retrospective nature of this manuscript, it was not possible to specifically investigate the exact incidence of pulmonary embolism in the study population, as not all patients underwent a thoracic computed tomography to address this question. Therefore, the number of patients with pulmonary embolism might be underestimated in this real-world population.

Indeed, this is the largest dataset available so far to investigate the benefits of a pre-existing oral anticoagulation with VKA or DOACs on outcomes in COVID-19. The sin-receptor blocker, DOAC directly acting oral anticoagulants. *Only significant results are listed

results from the logistic regression model were confirmed in a propensity match sensitivity analysis. In addition, this is the first study to report that an antiplatelet therapy does not impact the course of COVID-19. In comparison, a study from New York analyzed data from 2773 patients with COVID-19, of whom $28 \%$ received some kind of systemic anticoagulation during hospitalization [25]. No mortality difference in patients with or without systemic anticoagulation was demonstrated [25]. Patients on anticoagulation were more likely to need invasive ventilation [25]. However, there was a survival benefit for ventilated patients on anticoagulation if compared to those who were not anticoagulated [25]. Of note, the median time from hospital admission to the initiation of an anticoagulation was 2 days [25]. Importantly, the mortality risk declined with the duration of anticoagulation [25]. These findings explain why patients may benefit from a pre-existing oral anticoagulation in COVID-19. Several prospective studies to investigate the efficacy of oral or intravenous 
anticoagulation in COVID-19 patients are currently on the way.

A special attention needs to be drawn to those 53 patients in the study who received ECMO therapy as a bailout to insufficient mechanical ventilation therapy. Overall, the survival rate was $64 \%$. In the patient group $<60$ years, $74.2 \%$ survived, while in the age group $\geq 60$ years, $50 \%$ survived to discharge.

Given its retrospective nature, this study has several limitations. Although it is based on a large nationwide dataset, variations in terms of age, gender, social status, and morbidity amongst patients insured by different German healthcare providers cannot be excluded. Hospital data are of high quality, because disease codes and procedure codes are relevant for the amount of remuneration and are therefore verified by hospitals and sickness funds. Nevertheless, codes might be missing if there is no impact on remuneration. The presented claims data do not allow for detailed analysis of therapy changes during the index hospitalization, as the diagnoses are documented at the time of hospital discharge. However, it is unlikely that patients with an indication for oral anticoagulation would be deprived of their anticoagulants after hospital admission. A certain proportion of patients who were not on long-term anticoagulation before hospitalization will have received prophylactic anticoagulation in hospital. However, a prophylactic anticoagulation in-hospital would not explain why an anticoagulation with DOAC or VKA improves outcomes if compared to patients who were not on long-term oral anticoagulation. Long-term medication was defined as prescriptions of $\geq 90$ DDDs within 180 days. As such, cases where oral anticoagulation was stopped prior to admission for COVID-19 might have been miss-classified. However, as oral anticoagulation is commonly a long-term medication, these cases are assumed to be rare.

Moreover, autopsy results and post-mortem diagnoses are not reflected by the claim data. Therefore, the occurrence of thromboembolic events may be underestimated in this analysis, as highlighted above.

\section{Conclusion}

We present a large-scale Germany wide study to characterize COVID-19 hospitalizations. The main findings were that an antithrombotic therapy with VKA or DOACsbut not with antiplatelet therapy-was associated with improved outcomes, while ACE inhibitors did not impact on outcomes. Prospective randomized trials are needed to verify this hypothesis.
Acknowledgements Not applicable.

Author contribution GMF, CG, and EJ designed the study and drafted the manuscript. EJ, CG, and UE were responsible for data analysis, EJ, $\mathrm{CG}$, and UE guarantee for the integrity of the database. LA supported the writing process and data acquisition, HT, MR, AK, DL, CS, and UL supported the study design and revised the manuscript.

Funding No specific funding was necessary for the conduct of this study.

Data availability Data sharing is not applicable to this article as claim data were analyzed.

\section{Compliance with ethical standards}

Conflict of interest GMF reports speaker fees from Amgen and Boehringer Ingelheim and a research grant from Bayer. UL reports grants from Bayer, personal fees from Bayer, personal fees from Boehringer, personal fees from Daichy Sankyo, and personal fees from Pfizer, outside the submitted work.

Ethical approval The study complies with the Declaration of Helsinki and was authorized by the ethics committee of the Charité-University Hospital Berlin, Germany.

Informed consent All authors approved the current version and agreed to the Clinical Research in Cardiology submission policies. The manuscript has not been published and is not being considered for publication elsewhere in whole or part in any language.

\section{References}

1. University JH (2020) John Hopkins University covid-19. https:// coronavirus.jhu.edu/map.html.

2. Huang C, Wang Y, Li X, Ren L, Zhao J, Hu Y, Zhang L, Fan G, Xu J, Gu X, Cheng Z, Yu T, Xia J, Wei Y, Wu W, Xie X, Yin W, Li H, Liu M, Xiao Y, Gao H, Guo L, Xie J, Wang G, Jiang R, Gao Z, Jin Q, Wang J, Cao B (2020) Clinical features of patients infected with 2019 novel coronavirus in Wuhan, China. Lancet 395(10223):497-506. https://doi.org/10.1016/S0140 $-6736(20) 30183-5$

3. Bikdeli B, Madhavan MV, Jimenez D, Chuich T, Dreyfus I, Driggin E, Nigoghossian C, Ageno W, Madjid M, Guo Y, Tang LV, Hu Y, Giri J, Cushman M, Quere I, Dimakakos EP, Gibson CM, Lippi G, Favaloro EJ, Fareed J, Caprini JA, Tafur AJ, Burton JR, Francese DP, Wang EY, Falanga A, McLintock C, Hunt BJ, Spyropoulos AC, Barnes GD, Eikelboom JW, Weinberg I, Schulman S, Carrier M, Piazza G, Beckman JA, Steg PG, Stone GW, Rosenkranz S, Goldhaber SZ, Parikh SA, Monreal M, Krumholz HM, Konstantinides SV, Weitz JI, Lip GYH (2020) COVID-19 and thrombotic or thromboembolic disease: implications for prevention, antithrombotic therapy, and follow-up. J Am Coll Cardiol. https://doi.org/10.1016/j.jacc.2020.04.031

4. Klok FA, Kruip M, van der Meer NJM, Arbous MS, Gommers D, Kant KM, Kaptein FHJ, van Paassen J, Stals MAM, Huisman MV, Endeman H (2020) Incidence of thrombotic complications in critically ill ICU patients with COVID-19. Thromb Res. https ://doi.org/10.1016/j.thromres.2020.04.013

5. Wichmann D, Sperhake JP, Lutgehetmann M, Steurer S, Edler C, Heinemann A, Heinrich F, Mushumba H, Kniep I, Schroder AS, Burdelski C, de Heer G, Nierhaus A, Frings D, Pfefferle S, Becker 
H, Bredereke-Wiedling H, de Weerth A, Paschen HR, Sheikhzadeh-Eggers S, Stang A, Schmiedel S, Bokemeyer C, Addo MM, Aepfelbacher M, Puschel K, Kluge S (2020) Autopsy findings and venous thromboembolism in patients with COVID-19: a prospective cohort study. Ann Intern Med. https://doi.org/10.7326/ M20-2003

6. Ackermann M, Verleden SE, Kuehnel M, Haverich A, Welte T, Laenger F, Vanstapel A, Werlein C, Stark H, Tzankov A, Li WW, Li VW, Mentzer SJ, Jonigk D (2020) Pulmonary vascular endothelialitis, thrombosis, and angiogenesis in Covid-19. N Engl J Med. https://doi.org/10.1056/NEJMoa2015432

7. Coding I-ICD-10 coding. https://www.dimdi.de/static/de/klass ifikationen/icd/icd-10-gm/kode-suche/htmlgm2020/

8. Encoding Oap Operations and procedures encoding. https://www. dimdi.de/static/de/klassifikationen/ops/kode-suche/opshtml2020/

9. Drugs Aeo ATC encoding of drugs. https://www.dimdi.de/dynam $\mathrm{ic/de/das-dimdi/aktuelles/meldung/amtliche-atc-klassifikation-}$ mit-ddd-fuer-2020-veroeffentlicht/

10. Elixhauser A, Steiner C, Harris DR, Coffey RM (1998) Comorbidity measures for use with administrative data. Med Care 36(1):827. https://doi.org/10.1097/00005650-199801000-00004

11. Quan H, Sundararajan V, Halfon P, Fong A, Burnand B, Luthi JC, Saunders LD, Beck CA, Feasby TE, Ghali WA (2005) Coding algorithms for defining comorbidities in ICD-9-CM and ICD-10 administrative data. Med Care 43(11):1130-1139. https://doi. org/10.1097/01.mlr.0000182534.19832.83

12. Bohmer MM, Buchholz U, Corman VM, Hoch M, Katz K, Marosevic DV, Bohm S, Woudenberg T, Ackermann N, Konrad R, Eberle U, Treis B, Dangel A, Bengs K, Fingerle V, Berger A, Hormansdorfer S, Ippisch S, Wicklein B, Grahl A, Portner K, Muller N, Zeitlmann N, Boender TS, Cai W, Reich A, An der Heiden M, Rexroth U, Hamouda O, Schneider J, Veith T, Muhlemann B, Wolfel R, Antwerpen M, Walter M, Protzer U, Liebl B, Haas W, Sing A, Drosten C, Zapf A (2020) Investigation of a COVID-19 outbreak in Germany resulting from a single travelassociated primary case: a case series. Lancet Infect Dis. https:// doi.org/10.1016/S1473-3099(20)30314-5

13. Robert-Koch-Instititute (2020) Robert-Koch-Instititute. https:// www.rki.de/DE/Content/InfAZ/N/Neuartiges_Coronavirus/Steck brief.html\#doc13776792bodyText2

14. Richardson S, Hirsch JS, Narasimhan M, Crawford JM, McGinn T, Davidson KW, The Northwell C-RC, Barnaby DP, Becker LB, Chelico JD, Cohen SL, Cookingham J, Coppa K, Diefenbach MA, Dominello AJ, Duer-Hefele J, Falzon L, Gitlin J, Hajizadeh N, Harvin TG, Hirschwerk DA, Kim EJ, Kozel ZM, Marrast LM, Mogavero JN, Osorio GA, Qiu M, Zanos TP (2020) Presenting characteristics, comorbidities, and outcomes among 5700 patients hospitalized with COVID-19 in the New York City area. JAMA. https://doi.org/10.1001/jama.2020.6775

15. Karagiannidis C, Mostert C, Hentschker C, Voshaar T, Malzahn J, Schillinger G, Klauber J, Janssens U, Marx G, Weber-Carstens S, Kluge S, Pfeifer M, Grabenhenrich L, Welte T, Busse R (2020) Case characteristics, resource use, and outcomes of 10 021 patients with COVID-19 admitted to 920 German hospitals: an observational study. Lancet Respir Med 8(9):853-862. https:// doi.org/10.1016/S2213-2600(20)30316-7
16. Allers K, Hoffmann F (2018) Mortality and hospitalization at the end of life in newly admitted nursing home residents with and without dementia. Soc Psychiatry Psychiatr Epidemiol 53(8):833839. https://doi.org/10.1007/s00127-018-1523-0

17. Williamson EJ, Walker AJ, Bhaskaran K, Bacon S, Bates C, Morton CE, Curtis HJ, Mehrkar A, Evans D, Inglesby P, Cockburn J, McDonald HI, MacKenna B, Tomlinson L, Douglas IJ, Rentsch CT, Mathur R, Wong AYS, Grieve R, Harrison D, Forbes H, Schultze A, Croker R, Parry J, Hester F, Harper S, Perera R, Evans SJW, Smeeth L, Goldacre B (2020) Factors associated with COVID-19-related death using OpenSAFELY. Nature 584(7821):430-436. https://doi.org/10.1038/s41586-020-2521-4

18. Guan WJ, Ni ZY, Hu Y, Liang WH, Ou CQ, He JX, Liu L, Shan H, Lei CL, Hui DSC, Du B, Li LJ, Zeng G, Yuen KY, Chen RC, Tang CL, Wang T, Chen PY, Xiang J, Li SY, Wang JL, Liang ZJ, Peng YX, Wei L, Liu Y, Hu YH, Peng P, Wang JM, Liu JY, Chen Z, Li G, Zheng ZJ, Qiu SQ, Luo J, Ye CJ, Zhu SY, Zhong NS, China Medical Treatment Expert Group for C (2020) Clinical characteristics of coronavirus disease 2019 in China. N Engl J Med 382(18):1708-1720. https://doi.org/10.1056/NEJMoa2002 032

19. Nobile B, Durand M, Olie E, Guillaume S, Moles JP, Haffen E, Courtet P (2020) Clomipramine could be useful in preventing neurological complications of SARS-CoV-2 infection. J Neuroimmune Pharmacol 15(3):347-348. https://doi.org/10.1007/s1148 1-020-09939-2

20. Schloer S, Brunotte L, Goretzko J, Mecate-Zambrano A, Korthals N, Gerke V, Ludwig S, Rescher U (2020) Targeting the endolysosomal host-SARS-CoV-2 interface by clinically licensed functional inhibitors of acid sphingomyelinase (FIASMA) including the antidepressant fluoxetine. Emerg Microbes Infect. https://doi. org/10.1080/22221751.2020.1829082

21. Reynolds HR, Adhikari S, Pulgarin C, Troxel AB, Iturrate E, Johnson SB, Hausvater A, Newman JD, Berger JS, Bangalore S, Katz SD, Fishman GI, Kunichoff D, Chen Y, Ogedegbe G, Hochman JS (2020) Renin-angiotensin-aldosterone system inhibitors and risk of Covid-19. N Engl J Med. https://doi.org/10.1056/ NEJMoa2008975

22. Mancia G, Rea F, Ludergnani M, Apolone G, Corrao G (2020) Renin-angiotensin-aldosterone system blockers and the risk of Covid-19. N Engl J Med. https://doi.org/10.1056/NEJMoa2006 923

23. Levi M, Thachil J, Iba T, Levy JH (2020) Coagulation abnormalities and thrombosis in patients with COVID-19. Lancet Haematol. https://doi.org/10.1016/S2352-3026(20)30145-9

24. LaMori JC, Mody SH, Gross HJ, daCosta DM, Patel AA, Schein JR, Nelson WW (2013) Burden of comorbidities among patients with atrial fibrillation. Ther Adv Cardiovasc Dis 7(2):53-62. https ://doi.org/10.1177/1753944712464101

25. Paranjpe IFV, Lala A, Russak A, Glicksberg B, Levin A, Charney AW, Narula J, Fayad ZA, Bagiella E, Nadkarni GN (2020) Association of treatment dose anticoagulation with in-hospital survival among hospitalized patients with COVID-19. J Am Coll Cardial. https://doi.org/10.1016/j.jacc.2020.05.001 